Cite this: Phys. Chem. Chem. Phys., $2014,16,17295$

Received 2nd April 2014,

DOI: $10.1039 / c 4 c p 01432 d$

www.rsc.org/pccp Accepted 1st July 2014

\section{Proton dynamics of two-dimensional oxalate-bridged coordination polymers}

\author{
Satoshi Miyatsu, ${ }^{a}$ Maiko Kofu, ${ }^{a}$ Atsushi Nagoe, ${ }^{a b}$ Takeshi Yamada, ${ }^{a b}$ \\ Masaaki Sadakiyo, ${ }^{\text {cd }}$ Teppei Yamada, ${ }^{C}$ Hiroshi Kitagawa, ${ }^{\text {bc }}$ Madhusudan Tyagi, ${ }^{e}$ \\ Victoria García Sakai ${ }^{f}$ and Osamu Yamamuro*ab
}

\begin{abstract}
A two-dimensional porous coordination polymer $\left(\mathrm{NH}_{4}\right)_{2}\left\{\mathrm{HOOC}\left(\mathrm{CH}_{2}\right)_{4} \mathrm{COOH}\right\}\left[\mathrm{Zn}_{2}\left(\mathrm{C}_{2} \mathrm{O}_{4}\right)_{3}\right]$ (abbreviated as $\left(\mathrm{NH}_{4}\right)_{2}(\operatorname{adp})\left[\mathrm{Zn}_{2}(\mathrm{ox})_{3}\right]$ (adp = adipic acid, ox = oxalate)), which accommodates water molecules between the $\left[\mathrm{Zn}_{2}(\mathrm{ox})_{3}\right]$ layers, is highly remarked as a new type of crystalline proton conductor. In order to investigate its phase behavior and the proton conducting mechanism, we have performed adiabatic calorimetry, neutron diffraction, and quasi-elastic neutron scattering experiments on a fully hydrated sample $\left(\mathrm{NH}_{4}\right)_{2}(\mathrm{adp})\left[\mathrm{Zn}_{2}(\mathrm{ox})_{3}\right] \cdot 3 \mathrm{H}_{2} \mathrm{O}$ with the highest proton conductivity $\left(8 \times 10^{-3} \mathrm{~S} \mathrm{~cm}^{-1}, 25{ }^{\circ} \mathrm{C}, 98 \% \mathrm{RH}\right)$. Its isostructural derivative $\mathrm{K}_{2}(\mathrm{adp})\left[\mathrm{Zn}_{2}(\mathrm{ox})_{3}\right] \cdot 3 \mathrm{H}_{2} \mathrm{O}$ was also measured to investigate the role of ammonium ions. $\left(\mathrm{NH}_{4}\right)_{2}(\mathrm{adp})\left[\mathrm{Zn}_{2}(\mathrm{ox})_{3}\right] \cdot 3 \mathrm{H}_{2} \mathrm{O}$ and $\mathrm{K}_{2}(\mathrm{adp})\left[\mathrm{Zn}_{2}(\mathrm{ox})_{3}\right] \cdot 3 \mathrm{H}_{2} \mathrm{O}$ exhibit higher order transitions at $86 \mathrm{~K}$ and $138 \mathrm{~K}$, respectively. From the magnitude of the transition entropy, the former is of an order-disorder type while the latter is of a displacive type. $\left(\mathrm{NH}_{4}\right)_{2}(\mathrm{adp})\left[\mathrm{Zn}_{2}(\mathrm{Ox})_{3}\right] \cdot 3 \mathrm{H}_{2} \mathrm{O}$ has four Debye-type relaxations and $\mathrm{K}_{2}(\mathrm{adp})\left[\mathrm{Zn}_{2}(\mathrm{ox})_{3}\right] \cdot 3 \mathrm{H}_{2} \mathrm{O}$ has two similar relaxations above each transition temperature. The two relaxations of $\left(\mathrm{NH}_{4}\right)_{2}(\mathrm{adp})\left[\mathrm{Zn}_{2}(\mathrm{ox})_{3}\right] \cdot 3 \mathrm{H}_{2} \mathrm{O}$ with very small activation energies $\left(\Delta E_{\mathrm{a}}<5 \mathrm{~kJ} \mathrm{~mol}^{-1}\right)$ are due to the rotational motions of ammonium ions and play important roles in the proton conduction mechanism. It was also found that the protons in $\left(\mathrm{NH}_{4}\right)_{2}(\mathrm{adp})\left[\mathrm{Zn}_{2}(\mathrm{ox})_{3}\right] \cdot 3 \mathrm{H}_{2} \mathrm{O}$ are carried through a Grotthuss mechanism. We present a discussion on the proton conducting mechanism based on the present structural and dynamical information.
\end{abstract}

\section{Introduction}

Metal-organic frameworks (MOFs), which are composed of metal ions and organic ligands, have attracted much attention in the last decade due to their applications in gas sorption, ${ }^{1-3}$ catalysis, ${ }^{4,5}$ and ionic conductivity. ${ }^{6-12}$ They are often called porous coordination polymers (PCPs) because they commonly possess a porous structure, a key characteristic of MOFs since the architecture (e.g., size, dimensionality) can be controlled by changing metal ions and ligands. ${ }^{13-15}$

We have focused on PCPs exhibiting proton conductivity. High-performance proton conductors have an important role in

${ }^{a}$ Institute for Solid State Physics, University of Tokyo, 5-1-5 Kashiwanoha, Kashiwa, Chiba 277-8581, Japan. E-mail: yamamuro@issp.u-tokyo.ac.jp

${ }^{b}$ Core Research for Evolutional Science and Technology (CREST), Japan Science and Technology Agency (JST), 7 Gobancho, Chiyoda-ku, Tokyo 102-0076, Japan ${ }^{c}$ Graduate School of Science, Kyoto University, Kitashirakawa Oiwake-cho, Sakyo-ku, Kyoto 606-8502, Japan

${ }^{d}$ International Institute for Carbon-Neutral Energy Research (WPI-I2CNER), Kyushu University, 744 Moto-oka, Nishi-ku, Fukuoka 819-0395, Japan

${ }^{e}$ NIST Center for Neutron Research, National Institute of Standards and Technology, 100 Bureau Drive, Gaithersburg, Maryland 20899-6102, USA

${ }^{f}$ ISIS Facility, Rutherford Appleton Laboratory, Harwell Science \& Innovation Campus, Chilton, Didcot, OX11 oQX, UK fuel cell applications. ${ }^{16-18}$ Protons are supplied by acidic groups such as $-\mathrm{COOH}$ and $-\mathrm{OH}$ (sometimes $-\mathrm{NH}_{2}$ group) on the pore wall and are carried by molecules (in most cases, water molecules) inside the pore. ${ }^{19-21,23,24}$ For example, in copper rubeanate $\left(\mathrm{H}_{2} \mathrm{C}_{2} \mathrm{~N}_{2} \mathrm{~S}_{2} \mathrm{Cu} ; \mathrm{H}_{2}\right.$ dtoa $\left.\mathrm{Cu}\right)$, the proton conductivity is mainly governed by the protons provided by the $-\mathrm{NH}_{2}$ group in the pore wall. $\mathrm{H}_{2}$ dtoa $\mathrm{Cu}$ adsorbs water in its pores to a maximum hydration of 3.7 molecules at a relative humidity $(\mathrm{RH})$ of $100 \%$. The conductivity at this concentration is $0.01 \mathrm{~S} \mathrm{~cm}^{-1}$, comparable to that of Nafion, currently the best commercial proton conductor. Our quasi-elastic neutron scattering (QENS) study has revealed that the water inside the pore behaves as bulk water (or free water) above the phase transition temperature, and is condensed on the pore surface below this temperature. This free water plays an important role as the proton carrier. ${ }^{25,26}$

$\left(\mathrm{NH}_{4}\right)_{2}(\operatorname{adp})\left[\mathrm{Zn}_{2}(\mathrm{Ox})_{3}\right]($ adp $=$ adipic acid, ox = oxalate $)$ is one of the PCPs developed in recent years. It has been reported that $\left(\mathrm{NH}_{4}\right)_{2}(\operatorname{adp})\left[\mathrm{Zn}_{2}(\mathrm{ox})_{3}\right]$ adsorbs as many water molecules as copper rubeanate and the proton conductivity of the trihydrate sample $\left(\left(\mathrm{NH}_{4}\right)_{2}(\operatorname{adp})\left[\mathrm{Zn}_{2}(\mathrm{Ox})_{3}\right] \cdot 3 \mathrm{H}_{2} \mathrm{O}\right)$ is also $0.01 \mathrm{~S} \mathrm{~cm} \mathrm{~cm}^{-1} .^{22}$ Unlike copper rubeanate and Nafion which are amorphous solids, $\left(\mathrm{NH}_{4}\right)_{2}(\operatorname{adp})\left[\mathrm{Zn}_{2}(\mathrm{ox})_{3}\right]$ can be synthesized as single crystals, leading to more homogeneous samples with high reproducibility, 
(a)
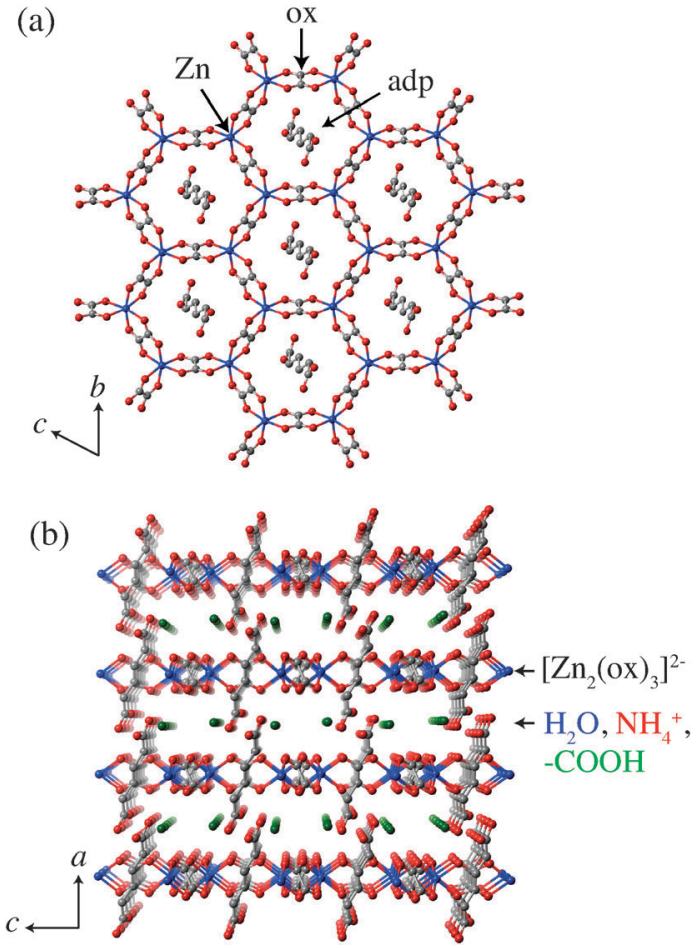

Fig. 1 (a) Perspective view along the a-axis of $\left(\mathrm{NH}_{4}\right)_{2}(\mathrm{adp})\left[\mathrm{Zn}_{2}(\mathrm{ox})_{3}\right]$. A honeycomb layer structure is formed by $\left[\mathrm{Zn}_{2}(\mathrm{Ox})_{3}\right]^{2-}$ and adp. (b) Perspective view along the $b$-axis of $\left(\mathrm{NH}_{4}\right)_{2}(\operatorname{adp})\left[\mathrm{Zn}_{2}(\mathrm{ox})_{3}\right] . \mathrm{H}_{2} \mathrm{O}, \mathrm{NH}_{4}{ }^{+}$, and $-\mathrm{COOH}$ groups are located between the layers. Red, green, gray, and blue colors correspond to oxygen, nitrogen, carbon, and zinc atoms, respectively. Water molecules are omitted.

on which very precise structural work can be performed to investigate the mechanism of proton conduction.

The crystal structure of $\left(\mathrm{NH}_{4}\right)_{2}(\mathrm{adp})\left[\mathrm{Zn}_{2}(\mathrm{ox})_{3}\right]$, determined by single-crystal X-ray diffraction measurements, ${ }^{22}$ is shown in Fig. 1. Two-dimensional honeycomb sheets are formed by an oxalated-bridged framework $\left[\mathrm{Zn}_{2}(\mathrm{Ox})_{3}\right]^{2-}$ and adipic acids penetrate the sheets nearly vertically. There are carboxyl groups of adipic acids, ammonium ions and water molecules in the space between the zinc oxalate layers. We call this space "proton conducting layers". It is presumed that protons are supplied by carboxyl groups and carried by water molecules and potentially by ammonium ions.

The first purpose of this study is to investigate the phase behavior of $\left(\mathrm{NH}_{4}\right)_{2}(\operatorname{adp})\left[\mathrm{Zn}_{2}(\mathrm{Ox})_{3}\right] \cdot 3 \mathrm{H}_{2} \mathrm{O}$ and clarify the relation between the phase transition, which is associated with water molecules and/or ammonium ions, and the proton conductivity. For this purpose, we have performed adiabatic calorimetry and neutron powder diffraction measurements at temperatures between 5 and $300 \mathrm{~K}$. Next, to reveal the proton-conducting mechanism, QENS measurements have been carried out in a time range between $0.1 \mathrm{ps}$ and $10 \mathrm{~ns}$. The incoherent neutron scattering cross-section of a hydrogen atom $\left(\sigma_{\text {inc }}=80 \mathrm{~b}\right.$, $1 \mathrm{~b}=10^{-24} \mathrm{~cm}^{2}$ ) is much larger than the incoherent/coherent cross-sections of other atoms such as carbon $\left(\sigma_{\text {inc }}=0 \mathrm{~b}\right)$, nitrogen $\left(\sigma_{\text {inc }}=0.5 \mathrm{~b}\right)$, oxygen $\left(\sigma_{\text {inc }}=0 \mathrm{~b}\right)$, and deuterium $\left(\sigma_{\text {inc }}=2.1 \mathrm{~b}\right)$. Therefore, the self-motions of molecules/ions/functional groups with hydrogen atoms are preferentially detected through the incoherent scattering from hydrogen atoms. For all experiments, we have also investigated $\mathrm{K}_{2}(\operatorname{adp})\left[\mathrm{Zn}_{2}(\mathrm{ox})_{3}\right] \cdot 3 \mathrm{H}_{2} \mathrm{O}$ in which ammonium ions are substituted by potassium ions. ${ }^{27}$ Since $\mathrm{K}_{2}(\mathrm{adp})\left[\mathrm{Zn}_{2}(\mathrm{ox})_{3}\right] \cdot 3 \mathrm{H}_{2} \mathrm{O}$ is isostructural with $\left(\mathrm{NH}_{4}\right)_{2}(\mathrm{adp})$ $\left[\mathrm{Zn}_{2}(\mathrm{ox})_{3}\right] \cdot 3 \mathrm{H}_{2} \mathrm{O}$, the comparison between the two samples is significant in revealing the function of ammonium ions. It should be pointed out that the proton conductivity of $\mathrm{K}_{2}(\operatorname{adp})\left[\mathrm{Zn}_{2}(\mathrm{ox})_{3}\right] \cdot 3 \mathrm{H}_{2} \mathrm{O}$ is $1.2 \times 10^{-4} \mathrm{~S} \mathrm{~cm}^{-1}\left(25{ }^{\circ} \mathrm{C}, 98 \% \mathrm{RH}\right)$, which is two orders of magnitude smaller than that of $\left(\mathrm{NH}_{4}\right)_{2}(\mathrm{adp})\left[\mathrm{Zn}_{2}(\mathrm{ox})_{3}\right] \cdot 3 \mathrm{H}_{2} \mathrm{O} .{ }^{27}$ In the last part of the paper, we discuss the mechanism of proton conductivity in $\left(\mathrm{NH}_{4}\right)_{2}(\operatorname{adp})$ $\left[\mathrm{Zn}_{2}(\mathrm{ox})_{3}\right] \cdot 3 \mathrm{H}_{2} \mathrm{O}$ on the basis of presently accessible structural and dynamical information.

\section{Experimental}

\subsection{Samples}

$\left(\mathrm{NH}_{4}\right)_{2}(\operatorname{adp})\left[\mathrm{Zn}_{2}(\mathrm{ox})_{3}\right] \cdot 3 \mathrm{H}_{2} \mathrm{O}$ was prepared by a hydrothermal method with zinc oxide, adipamide, and $\mathrm{H}_{2}(\mathrm{ox}) \cdot 2 \mathrm{H}_{2} \mathrm{O}$ in water using an autoclave at $130{ }^{\circ} \mathrm{C}$. In order to remove bulk water and ensure adsorption equilibrium, the sample was kept in a glove bag with relative humidity $\mathrm{RH}=98 \%$ for a few hours. After this procedure, all sample handling was done in a glove bag at $\mathrm{RH}$ $>95 \%$, to avoid transformation of the trihydrate into the dihydrate form below $85 \% \mathrm{RH}^{22} \mathrm{~K}_{2}(\mathrm{adp})\left[\mathrm{Zn}_{2}(\mathrm{ox})_{3}\right] \cdot 3 \mathrm{H}_{2} \mathrm{O}$ was synthesized from a mixture of zinc oxide, adipic acid, $\mathrm{K}_{2}(\mathrm{ox}) \cdot \mathrm{H}_{2} \mathrm{O}$, and $\mathrm{H}_{2}$ (ox) $\cdot 2 \mathrm{H}_{2} \mathrm{O}$ in a water solvent using an autoclave at $130{ }^{\circ} \mathrm{C} .{ }^{27}$ The sample was handled in the same manner.

In the neutron scattering experiments, the methylene chains of adipic acid were deuterated in both $\left(\mathrm{NH}_{4}\right)_{2}(\operatorname{adp})\left[\mathrm{Zn}_{2}(\mathrm{ox})_{3}\right] \cdot 3 \mathrm{H}_{2} \mathrm{O}$ and $\mathrm{K}_{2}(\operatorname{adp})\left[\mathrm{Zn}_{2}(\mathrm{ox})_{3}\right] \cdot 3 \mathrm{H}_{2} \mathrm{O}$, such that their contribution to the scattering signal is low, and the majority arises from the motions of the water, ammonium ions, and carboxyl groups.

\subsection{Adiabatic calorimetry}

The heat capacity measurements were performed using a custom-built adiabatic calorimeter. ${ }^{28}$ In adiabatic calorimetry, the heat exchange between the sample and the environment is virtually eliminated and the heat capacity is obtained from a simple relation $C=\Delta E / \Delta T$. The technique gives the most accurate absolute value of the heat capacity, with a precision and an accuracy of 0.05 and $0.1 \%$, respectively.

$\left(\mathrm{NH}_{4}\right)_{2}(\mathrm{adp})\left[\mathrm{Zn}_{2}(\mathrm{ox})_{3}\right] \cdot 3 \mathrm{H}_{2} \mathrm{O}\left(0.4153 \mathrm{~g} ; 6.581 \times 10^{-4} \mathrm{~mol}\right)$ was loaded into the sample cell with helium gas $(0.1 \mathrm{MPa})$ for heat exchange, and the cell was sealed with an indium gasket. The temperature range for the heat capacity measurements was from 5 to $300 \mathrm{~K}$. The temperature increment was $0.5 \mathrm{~K}$ at around $5 \mathrm{~K}$, gradually increasing up to $2.5 \mathrm{~K}$ at around $300 \mathrm{~K}$. The heat capacity of $\mathrm{K}_{2}(\mathrm{adp})\left[\mathrm{Zn}_{2}(\mathrm{ox})_{3}\right] \cdot 3 \mathrm{H}_{2} \mathrm{O}\left(1.001 \mathrm{~g} ; 1.487 \times 10^{-3} \mathrm{~mol}\right)$ was measured in the same way.

\subsection{Neutron scattering}

The dynamics of the molecules and ions in the proton-conducting layers of $\left(\mathrm{NH}_{4}\right)_{2}(\operatorname{adp})\left[\mathrm{Zn}_{2}(\mathrm{ox})_{3}\right] \cdot 3 \mathrm{H}_{2} \mathrm{O}$ and $\mathrm{K}_{2}(\operatorname{adp})\left[\mathrm{Zn}_{2}(\mathrm{ox})_{3}\right] \cdot 3 \mathrm{H}_{2} \mathrm{O}$ 
were probed using three neutron spectrometers with different energy resolutions, to cover timescales between 0.1 ps and $10 \mathrm{~ns}$ (five orders of magnitude).

2.3.1 AGNES (direct geometry, time-of-flight type). We have performed elastic fixed-window scans and QENS measurements of $\left(\mathrm{NH}_{4}\right)_{2}(\operatorname{adp})\left[\mathrm{Zn}_{2}(\mathrm{ox})_{3}\right] \cdot 3 \mathrm{H}_{2} \mathrm{O}$ on AGNES. AGNES is a time-offlight chopper spectrometer which is owned by the Institute for Solid State Physics (ISSP), University of Tokyo. This instrument is installed on a cold neutron guide (C3-1) of JRR-3, Japan Atomic Energy Agency (JAEA). ${ }^{29,30}$ Neutrons with a wavelength of $4.22 \AA$ (for the standard mode) or $5.50 \AA$ (for the high resolution mode) are extracted with an array of five pyrolytic graphite (PG) (002) monochromators and pulsed using a double Fermi chopper. The pulsed neutrons are scattered by the sample and detected using $328{ }^{3} \mathrm{He}$ detector tubes arranged in a wide detector bank covering the scattering angles $(2 \theta)$ between $10^{\circ}$ and $130^{\circ}$. The energy resolutions (full-width at half maximum) and the energy windows are $\Delta E_{\mathrm{res}}=120 \mu \mathrm{eV}$ and $-20 \mathrm{meV}<\hbar \omega<3 \mathrm{meV}$ in the standard mode and $\Delta E_{\mathrm{res}}=$ $49 \mu \mathrm{eV}$ and $-10 \mathrm{meV}<\hbar \omega<1.5 \mathrm{meV}$ in the high resolution mode. These settings correspond to time ranges between 0.1 and $50 \mathrm{ps}$ and 1 and $100 \mathrm{ps}$, in the standard and high resolution modes, respectively.

In the fixed window scans at the standard mode, the intensity was recorded at $25 \mathrm{~K}, 50 \mathrm{~K}, 75 \mathrm{~K}, 100 \mathrm{~K}, 125 \mathrm{~K}$, $150 \mathrm{~K}, 170 \mathrm{~K}$, and every $10 \mathrm{~K}$ from $190 \mathrm{~K}$ to $300 \mathrm{~K}$. Data were collected for $40 \mathrm{mins}$ for each point. The QENS data were recorded in both modes at $10 \mathrm{~K}$ (for resolution), $100 \mathrm{~K}, 120 \mathrm{~K}$, $150 \mathrm{~K}, 180 \mathrm{~K}, 210 \mathrm{~K}, 240 \mathrm{~K}$, and $300 \mathrm{~K}$ with a counting time of $12 \mathrm{~h}$.

2.3.2 IRIS (inverted geometry, time-of-flight type). We have performed the elastic fixed-window scans, QENS, and neutron powder diffraction measurements of $\left(\mathrm{NH}_{4}\right)_{2}(\operatorname{adp})\left[\mathrm{Zn}_{2}(\mathrm{ox})_{3}\right] \cdot 3 \mathrm{H}_{2} \mathrm{O}$ and $\mathrm{K}_{2}(\operatorname{adp})\left[\mathrm{Zn}_{2}(\mathrm{ox})_{3}\right] \cdot 3 \mathrm{H}_{2} \mathrm{O}$ on IRIS. IRIS is a time-of-flight crystal analyzer spectrometer with diffraction capabilities located at the ISIS facility, Rutherford Appleton Laboratory (RAL), UK. ${ }^{31}$ In the QENS measurements, neutrons scattered from a sample are energy-analyzed by means of Bragg reflection from one of two large single crystal arrays (PG and muscovite mica) in close to backscattering geometry $\left(2 \theta_{\mathrm{B}}=175^{\circ}\right.$ where $\theta_{\mathrm{B}}$ is the Bragg angle of the analyzer crystal) and are counted in the detector array $\left(27^{\circ}<2 \theta<158^{\circ}\right)$. The diffraction bank at $2 \theta=170^{\circ}$ enables us to measure the diffraction pattern simultaneously with QENS data in the range of the scattering vector, $1.6 \AA^{-1}<Q<2.1 \AA^{-1}$. This bank is not for full structural analysis but for checking the structural change during the QENS measurement. In this study, IRIS was operated in the $\mathrm{PG}(002)$ configuration which provides an energy window of $-0.5 \mathrm{meV}<\hbar \omega<0.5 \mathrm{meV}$ and an energy resolution $\Delta E_{\mathrm{res}}$ of $17.5 \mu \mathrm{eV}$, covering the relaxation time ranging from $10 \mathrm{ps}$ to $150 \mathrm{ps}$.

In the fixed window scans, the intensity was recorded at $3.5 \mathrm{~K}$ and at every $10 \mathrm{~K}$ from $10 \mathrm{~K}$ to $300 \mathrm{~K}$. The QENS data were collected at $5 \mathrm{~K}$ (for resolution), $100 \mathrm{~K}, 120 \mathrm{~K}, 150 \mathrm{~K}, 180 \mathrm{~K}$, $210 \mathrm{~K}, 240 \mathrm{~K}, 270 \mathrm{~K}$, and $300 \mathrm{~K}$ with a counting time of $4 \mathrm{~h}$ for $\left(\mathrm{NH}_{4}\right)_{2}(\operatorname{adp})\left[\mathrm{Zn}_{2}(\mathrm{ox})_{3}\right] \cdot 3 \mathrm{H}_{2} \mathrm{O}$ and at $210 \mathrm{~K}, 240 \mathrm{~K}, 270 \mathrm{~K}$, and $300 \mathrm{~K}$ with a counting time of $6 \mathrm{~h}$ for $\mathrm{K}_{2}(\operatorname{adp})\left[\mathrm{Zn}_{2}(\mathrm{ox})_{3}\right] \cdot 3 \mathrm{H}_{2} \mathrm{O}$.
The diffraction patterns were simultaneously recorded at every measurement temperature.

2.3.3 HFBS (inverted geometry, continuous type). We have measured $\left(\mathrm{NH}_{4}\right)_{2}(\operatorname{adp})\left[\mathrm{Zn}_{2}(\mathrm{ox})_{3}\right] \cdot 3 \mathrm{H}_{2} \mathrm{O}$ and $\mathrm{K}_{2}(\operatorname{adp})\left[\mathrm{Zn}_{2}(\mathrm{ox})_{3}\right]$. $3 \mathrm{H}_{2} \mathrm{O}$ on HFBS. HFBS is a backscattering spectrometer installed on the NG2 guide at the NIST Center for Neutron Research in Gaithersburg, MD, USA. ${ }^{32}$ The HFBS instrument was operated in both the fixed window and dynamic window modes. In the dynamic window mode (QENS measurement conditions), the neutrons are Doppler shifted, providing a neutron wavelength band with its center at $6.27 \AA$. The neutrons scattered from the sample are energy-analyzed by means of Bragg reflection from $\mathrm{Si}(111)$ analyzers at $2.08 \mathrm{meV}$, and counted on ${ }^{3} \mathrm{He}$ detector tubes. In this experiment, we used an energy window, $-17 \mu \mathrm{eV}$ $<\hbar \omega<17 \mu \mathrm{eV}$, set by a Doppler frequency of $24 \mathrm{~Hz}$. The energy resolution was $0.8 \mu \mathrm{eV}$, which can cover the range of relaxation time from $100 \mathrm{ps}$ to $10 \mathrm{~ns}$. In the fixed window mode, the Doppler drive was stopped and only elastic scattering was recorded.

The fixed window scan was performed from $4 \mathrm{~K}$ to $285 \mathrm{~K}$ continuously at a rate of $1 \mathrm{~K} \mathrm{~min}^{-1}$. The QENS data were recorded at $4 \mathrm{~K}$ (for resolution), $65 \mathrm{~K}, 70 \mathrm{~K}, 75 \mathrm{~K}, 80 \mathrm{~K}, 90 \mathrm{~K}$, $100 \mathrm{~K}, 120 \mathrm{~K}, 150 \mathrm{~K}, 180 \mathrm{~K}, 200 \mathrm{~K}, 220 \mathrm{~K}$, and $260 \mathrm{~K}$ for $\left(\mathrm{NH}_{4}\right)_{2}(\operatorname{adp})\left[\mathrm{Zn}_{2}(\mathrm{ox})_{3}\right] \cdot 3 \mathrm{H}_{2} \mathrm{O}$ and at $100 \mathrm{~K}, 180 \mathrm{~K}, 200 \mathrm{~K}, 220 \mathrm{~K}$, $240 \mathrm{~K}, 270 \mathrm{~K}$, and $300 \mathrm{~K}$ for $\mathrm{K}_{2}(\operatorname{adp})\left[\mathrm{Zn}_{2}(\mathrm{ox})_{3}\right] \cdot 3 \mathrm{H}_{2} \mathrm{O}$. The counting time was $10 \mathrm{~h}$ for each QENS measurement.

\section{Results and discussion}

\subsection{Adiabatic calorimetry}

Fig. 2 and 3 show the heat capacities of $\left(\mathrm{NH}_{4}\right)_{2}(\operatorname{adp})\left[\mathrm{Zn}_{2}(\mathrm{ox})_{3}\right] \cdot 3 \mathrm{H}_{2} \mathrm{O}$ and $\mathrm{K}_{2}(\mathrm{adp})\left[\mathrm{Zn}_{2}(\mathrm{ox})_{3}\right] \cdot 3 \mathrm{H}_{2} \mathrm{O}$, respectively. Both $\left(\mathrm{NH}_{4}\right)_{2}(\mathrm{adp})\left[\mathrm{Zn}_{2}(\mathrm{ox})_{3}\right]$. $3 \mathrm{H}_{2} \mathrm{O}$ and $\mathrm{K}_{2}(\mathrm{adp})\left[\mathrm{Zn}_{2}(\mathrm{ox})_{3}\right] \cdot 3 \mathrm{H}_{2} \mathrm{O}$ exhibited phase transitions at $86 \mathrm{~K}$ and $138 \mathrm{~K}$, respectively. They both are higher order transitions without latent heat. This is confirmed by temperature drifts after heating; an endothermic drift is usually observed in first order transitions. The transition in $\left(\mathrm{NH}_{4}\right)_{2}(\operatorname{adp})\left[\mathrm{Zn}_{2}(\mathrm{ox})_{3}\right] \cdot 3 \mathrm{H}_{2} \mathrm{O}$ is

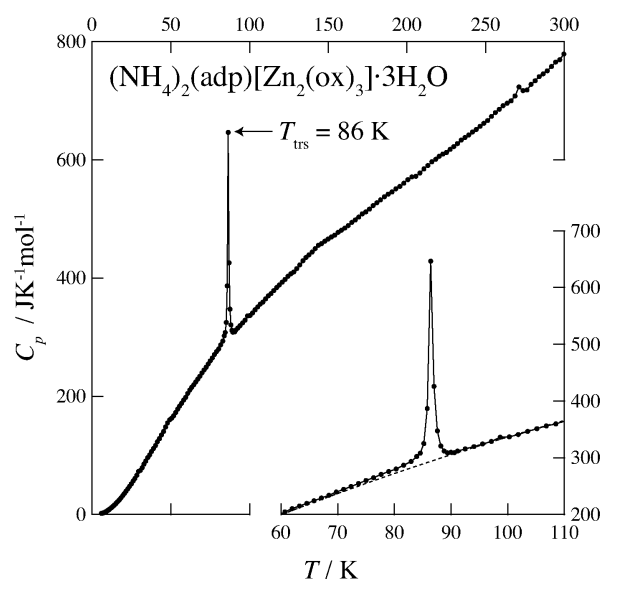

Fig. 2 Heat capacity of $\left(\mathrm{NH}_{4}\right)_{2}(\operatorname{adp})\left[\mathrm{Zn}_{2}(\mathrm{ox})_{3}\right] \cdot 3 \mathrm{H}_{2} \mathrm{O}$. The inset shows an enlarged plot around the phase transition. The dashed line represents the baseline for the transition. See text for the details. 


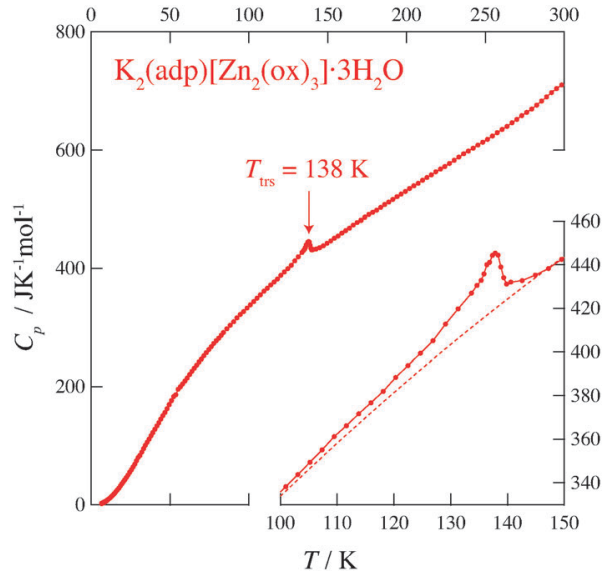

Fig. 3 Heat capacity of $\mathrm{K}_{2}(\mathrm{adp})\left[\mathrm{Zn}_{2}(\mathrm{ox})_{3}\right] \cdot 3 \mathrm{H}_{2} \mathrm{O}$. The inset shows an enlarged plot around the phase transition. The dashed line represents the baseline for the transition. See text for the details.

accompanied by a $\lambda$-type heat capacity anomaly. On the other hand, the heat capacity exhibits a step-like anomaly at the transition temperature in $\mathrm{K}_{2}(\mathrm{adp})\left[\mathrm{Zn}_{2}(\mathrm{ox})_{3}\right] \cdot 3 \mathrm{H}_{2} \mathrm{O}$. To estimate the entropy change at the transitions, the baseline $C_{\text {base }}$ was estimated by fitting the heat capacities to a quartic function in the temperature range from $60 \mathrm{~K}$ to $80 \mathrm{~K}$ (below $T_{\text {trs }}$ ) and from $90 \mathrm{~K}$ to $130 \mathrm{~K}$ (above $T_{\text {trs }}$ ). For $\mathrm{K}_{2}(\operatorname{adp})\left[\mathrm{Zn}_{2}(\mathrm{ox})_{3}\right] \cdot 3 \mathrm{H}_{2} \mathrm{O}$, the heat capacities were fitted by a cubic function in the temperature range from $70 \mathrm{~K}$ to $100 \mathrm{~K}$ and from $150 \mathrm{~K}$ to $200 \mathrm{~K}$. The baselines are shown as the dashed lines in Fig. 2 and 3. The transition entropy $\Delta_{\mathrm{trS}} S$ as a function of temperature is evaluated from the equation:

$$
\Delta_{\mathrm{trs}} S(T)=\int_{0}^{T} \frac{C_{p}-C_{\text {base }}}{T} \mathrm{~d} T^{\prime} .
$$

Fig. 4 shows the transition entropies for $\left(\mathrm{NH}_{4}\right)_{2}(\mathrm{adp})$ $\left[\mathrm{Zn}_{2}(\mathrm{ox})_{3}\right] \cdot 3 \mathrm{H}_{2} \mathrm{O}$ and $\mathrm{K}_{2}(\mathrm{adp})\left[\mathrm{Zn}_{2}(\mathrm{ox})_{3}\right] \cdot 3 \mathrm{H}_{2} \mathrm{O}$. The former drastically increases at $T=86 \mathrm{~K}$ while the latter gradually increases

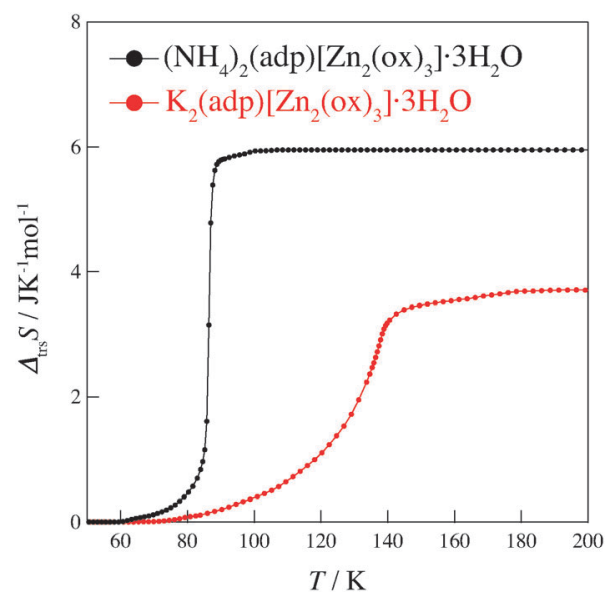

Fig. 4 Transition entropies of $\left(\mathrm{NH}_{4}\right)_{2}(\mathrm{adp})\left[\mathrm{Zn} \mathrm{n}_{2}(\mathrm{Ox})_{3}\right] \cdot 3 \mathrm{H}_{2} \mathrm{O}$ (black) and $\mathrm{K}_{2}(\mathrm{adp})\left[\mathrm{Zn}_{2}(\mathrm{Ox})_{3}\right] \cdot 3 \mathrm{H}_{2} \mathrm{O}(\mathrm{red})$. in a wide range of temperature. The total (integrated) transition entropies of $\left(\mathrm{NH}_{4}\right)_{2}(\mathrm{adp})\left[\mathrm{Zn}_{2}(\mathrm{ox})_{3}\right] \cdot 3 \mathrm{H}_{2} \mathrm{O}$ and $\mathrm{K}_{2}(\mathrm{adp})\left[\mathrm{Zn}_{2}(\mathrm{ox})_{3}\right]$. $3 \mathrm{H}_{2} \mathrm{O}$ are estimated to be $5.95 \pm 0.74 \mathrm{~J} \mathrm{~K}^{-1} \mathrm{~mol}^{-1}$ and $3.70 \pm$ $1.56 \mathrm{~J} \mathrm{~K}^{-1} \mathrm{~mol}^{-1}$, respectively. The uncertainty of the transition entropy is due to the arbitrary properties of the baseline; various temperature regions and various orders of polynomial function for the fitting were tested to estimate the uncertainty of the baseline. The transition entropy of $5.95 \mathrm{~J} \mathrm{~K}^{-1} \mathrm{~mol}^{-1}$ is close to $R \ln 2\left(=5.76 \mathrm{~J} \mathrm{~K}^{-1} \mathrm{~mol}^{-1}\right)$, suggesting that the transition at $86 \mathrm{~K}$ is an order-disorder phase transition. This may be due to ammonium ions since no ordering transition is observed in $\mathrm{K}_{2}(\mathrm{adp})\left[\mathrm{Zn}_{2}(\mathrm{ox})_{3}\right] \cdot 3 \mathrm{H}_{2} \mathrm{O}$ and the transition associated with water molecules usually occurs at higher temperatures due to strong intermolecular hydrogen bonds. On the other hand, the transition entropy of $\mathrm{K}_{2}(\operatorname{adp})\left[\mathrm{Zn}_{2}(\mathrm{ox})_{3}\right] \cdot 3 \mathrm{H}_{2} \mathrm{O}$ $\left(3.70 \pm 1.56 \mathrm{~J} \mathrm{~K}^{-1} \mathrm{~mol}^{-1}\right)$ is smaller than $R \ln 2$, so that we consider this transition is of a displacive type.

\subsection{Neutron powder diffraction}

Fig. 5 shows two-dimensional contour intensity maps obtained from the neutron powder diffraction measurements on IRIS. The intensity is given on a logarithmic scale in order to make weak Bragg peaks as well as strong peaks visible.

In $\left(\mathrm{NH}_{4}\right)_{2}(\mathrm{adp})\left[\mathrm{Zn}_{2}(\mathrm{ox})_{3}\right] \cdot 3 \mathrm{H}_{2} \mathrm{O}$, the Bragg peaks located at $Q=1.60-1.64 \AA^{-1}$ drastically changed at the transition temperature $86 \mathrm{~K}$. It should be noted that we could not recognize a significant structural change between $50 \mathrm{~K}$ and $100 \mathrm{~K}$ by singlecrystal X-ray diffraction measurements. These results indicate that the phase transition is associated with hydrogen atoms; the hydrogen atoms are hardly detectable by X-rays. The present data also demonstrate that the deuteration of the methylene
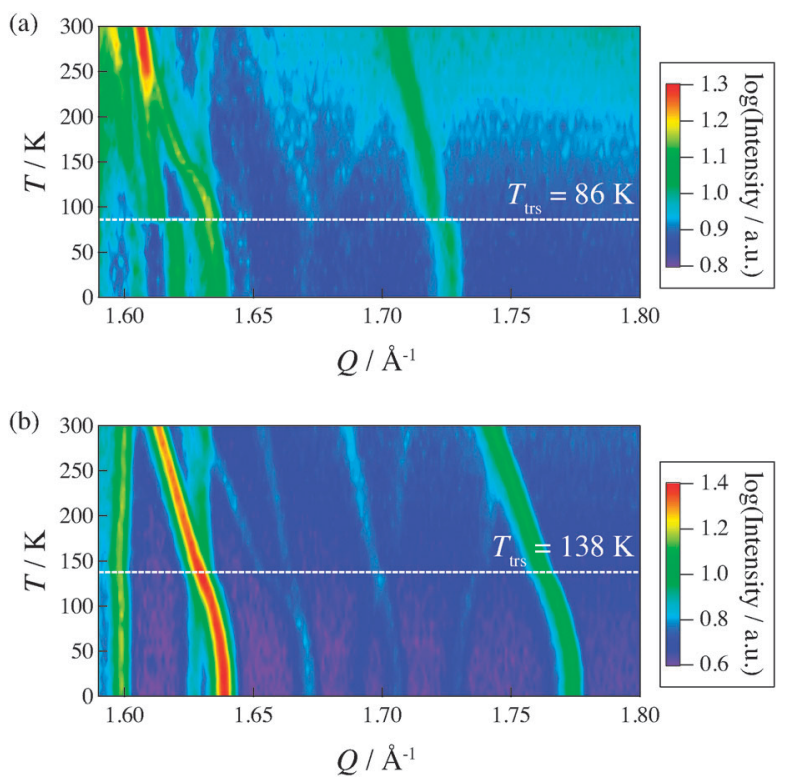

Fig. 5 Two-dimensional intensity maps obtained by neutron powder diffraction on IRIS for (a) $\left(\mathrm{NH}_{4}\right)_{2}(\operatorname{adp})\left[\mathrm{Zn}_{2}(\mathrm{ox})_{3}\right] \cdot 3 \mathrm{H}_{2} \mathrm{O}$ and (b) $\mathrm{K}_{2}(\mathrm{adp})\left[\mathrm{Zn}_{2}(\mathrm{ox})_{3}\right]$. $3 \mathrm{H}_{2} \mathrm{O}$. The intensity is given on a logarithmic scale. The white dashed line represents each transition temperature. 
chain of adipic acid does not change the transition temperature much.

In $\mathrm{K}_{2}(\mathrm{adp})\left[\mathrm{Zn}_{2}(\mathrm{ox})_{3}\right] \cdot 3 \mathrm{H}_{2} \mathrm{O}$, the weak peaks at $1.67 \AA^{-1}$ and $1.70 \AA^{-1}$ split above $T_{\text {trs }}=138 \mathrm{~K}$. Also, the position of Bragg peaks at $1.66 \AA^{-1}$ and $1.74 \AA^{-1}$ changed at the transition temperature. Unlike in the case of $\left(\mathrm{NH}_{4}\right)_{2}(\operatorname{adp})\left[\mathrm{Zn}_{2}(\mathrm{ox})_{3}\right]$. $3 \mathrm{H}_{2} \mathrm{O}$, the change in the diffraction pattern occurs gradually, which is consistent with the fact that the transition entropy gradually changes over a wide temperature range (see Section 3.1). To gain more insight into the arrangement of hydrogen atoms, further accurate neutron diffraction studies are required.

\subsection{Mean square displacement}

To investigate the temperature at which relaxation processes are activated within the time window of a given spectrometer, the mean square displacement, $\left\langle u^{2}\right\rangle$, was obtained from an elastic fixed window scan. In the fixed window scan, we measure the elastic intensity $I(Q, T)$ as a function of scattering vector $Q$ and temperature $T$; the intensity is integrated around $\hbar \omega=0$ over a fixed energy region corresponding to the instrumental resolution. The mean square displacement, $\left\langle u^{2}\right\rangle$, is evaluated from the equation

$$
\frac{I(Q, T)}{I\left(Q, T_{\min }\right)}=\exp \left[-\frac{1}{3} Q^{2}\left(\left\langle u^{2}\right\rangle-\left\langle u^{2}\right\rangle_{\min }\right)\right] \text {. }
$$

Here, the elastic intensity is normalized to the value at the minimum temperature $T_{\min } ;\left\langle u^{2}\right\rangle_{\min }$ corresponds to the mean square displacement at $T=T_{\min } \cdot\left\langle u^{2}\right\rangle$ which varies linearly with respect to temperature for a harmonic oscillator and so the deviation from the straight line indicates the occurrence of anharmonic vibration and/or relaxation in the samples.

Fig. 6 shows the mean square displacements taken on the three neutron spectrometers with different energy resolutions. As for $\left(\mathrm{NH}_{4}\right)_{2}(\operatorname{adp})\left[\mathrm{Zn}_{2}(\mathrm{ox})_{3}\right] \cdot 3 \mathrm{H}_{2} \mathrm{O},\left\langle u^{2}\right\rangle$ drastically increases above a temperature between 50 and $100 \mathrm{~K}$, indicating the onset of a relaxation. It is noteworthy that $\left\langle u^{2}\right\rangle$ deviates from

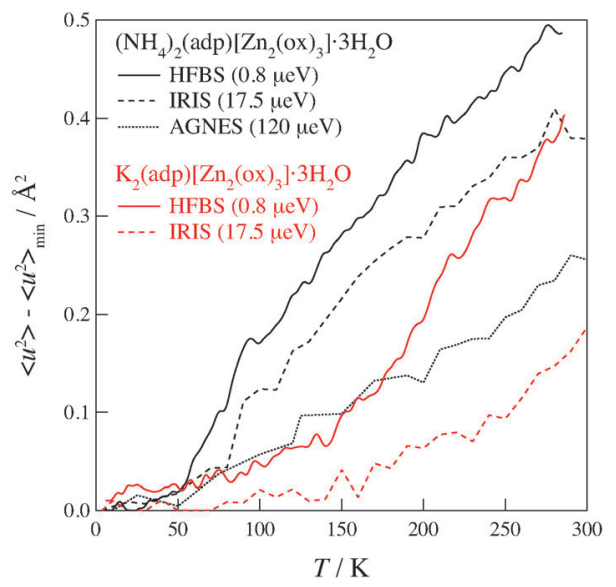

Fig. 6 Mean square displacements of $\left(\mathrm{NH}_{4}\right)_{2}(\mathrm{adp})\left[\mathrm{Zn}_{2}(\mathrm{ox})_{3}\right] \cdot 3 \mathrm{H}_{2} \mathrm{O}$ (black line) and $\mathrm{K}_{2}(\mathrm{adp})\left[\mathrm{Zn}_{2}(\mathrm{ox})_{3}\right] \cdot 3 \mathrm{H}_{2} \mathrm{O}$ (red line) as functions of temperature. The number in the parenthesis denotes the energy resolution of each instrument. The solid, dashed, and dotted lines correspond to the data taken on HFBS, IRIS, and AGNES, respectively. the linear relationship at $50 \mathrm{~K}$ in HFBS data, at $80 \mathrm{~K}$ in IRIS data, and at $100 \mathrm{~K}$ in AGNES data. It is reasonable that the HFBS data exhibit a lower onset temperature than the AGNES data, because a slower motion can be observed by an instrument with a higher energy resolution at a given temperature. The deviation also occurred at around $140 \mathrm{~K}$ in $\mathrm{K}_{2}(\operatorname{adp})\left[\mathrm{Zn}_{2}(\mathrm{ox})_{3}\right]$. $3 \mathrm{H}_{2} \mathrm{O}$. One can naturally understand that the motions of hydrogen atoms get activated above the phase transition temperatures, since the high-temperature (disordered) phase usually has a loosely packed and/or weakly interacting structure. It is exceptional and interesting that the excess increase of $\left\langle u^{2}\right\rangle$ appeared even below the transition temperature $(86 \mathrm{~K})$ in $\left(\mathrm{NH}_{4}\right)_{2}(\operatorname{adp})\left[\mathrm{Zn}_{2}(\mathrm{ox})_{3}\right] \cdot 3 \mathrm{H}_{2} \mathrm{O}$.

\subsection{Quasi-elastic neutron scattering}

3.4.1 Analyses of QENS spectra. In order to examine the relaxational dynamics precisely, we have carried out QENS measurements of $\left(\mathrm{NH}_{4}\right)_{2}(\operatorname{adp})\left[\mathrm{Zn}_{2}(\mathrm{ox})_{3}\right] \cdot 3 \mathrm{H}_{2} \mathrm{O}$ and $\mathrm{K}_{2}(\operatorname{adp})\left[\mathrm{Zn}_{2}(\mathrm{ox})_{3}\right]$. $3 \mathrm{H}_{2} \mathrm{O}$ using the three spectrometers having different energy resolutions. Fig. 7 shows, as an example, the dynamic structure factor, $S(Q, \omega)$, observed at $Q \simeq 1.25 \AA^{-1}$ and $T=120 \mathrm{~K}$, taken on the three spectrometers. The data were fitted to the following equations:

$$
\begin{gathered}
S(Q, \omega)=R(Q, \omega) \otimes\left\{\delta(\omega)+\sum_{i} L_{i}(Q, \omega)\right\}+\mathrm{BG}, \\
L_{i}(Q, \omega)=\frac{1}{\pi} \frac{\Gamma(Q)}{\omega^{2}+\Gamma^{2}(Q)},
\end{gathered}
$$

where $R(Q, \omega)$ is the resolution function of each instrument. A delta function $\delta(\omega)$ is attributed to the static component (or much slower motion than the instrumental resolution) mainly from hydrogen atoms and slightly from the coherent scattering contribution from other atoms, whereas $L_{i}(Q, \omega)$ describes the relaxations of hydrogen atoms. In the case where the relaxation function is represented as a simple exponential decay (Debye relaxation), $L_{i}(Q, \omega)$ is expressed by Lorentz functions as given in eqn (4). $\Gamma(Q)$ is the half width at half maximum (HWHM) of the Lorentz function. The subscript of $L_{i}(Q, \omega)$ implies that there exist multiple relaxation modes in the system. Since the number of observable relaxations depends on the energy resolution and window of the instrument, we accordingly change the number of Lorentz functions. BG is the constant background. The fitting procedures were carried out using the PAN program on the DAVE software. ${ }^{33}$ The fits converged well at all $Q$ s and temperatures for all spectrometers. The results of the fits were satisfactory as shown in Fig. 7.

To obtain the spatial information on the relaxations, we investigated the $Q$-dependence of the relaxations. The $Q$ regions where strong diffraction peaks appear were omitted from the analysis. Fig. 8 displays $\Gamma$ as a function of $Q$ at 120,180, and $240 \mathrm{~K}$ on AGNES and at 100 and $220 \mathrm{~K}$ on HFBS. No pronounced $Q$-dependence of $\Gamma$ implies that these motions of hydrogen atoms are of a local origin. In the measurements on IRIS, similar behavior was observed. Hence, all of the hydrogen motions observed in $\left(\mathrm{NH}_{4}\right)_{2}(\mathrm{adp})\left[\mathrm{Zn}_{2}(\mathrm{Ox})_{3}\right] \cdot 3 \mathrm{H}_{2} \mathrm{O}$ are local relaxations. 

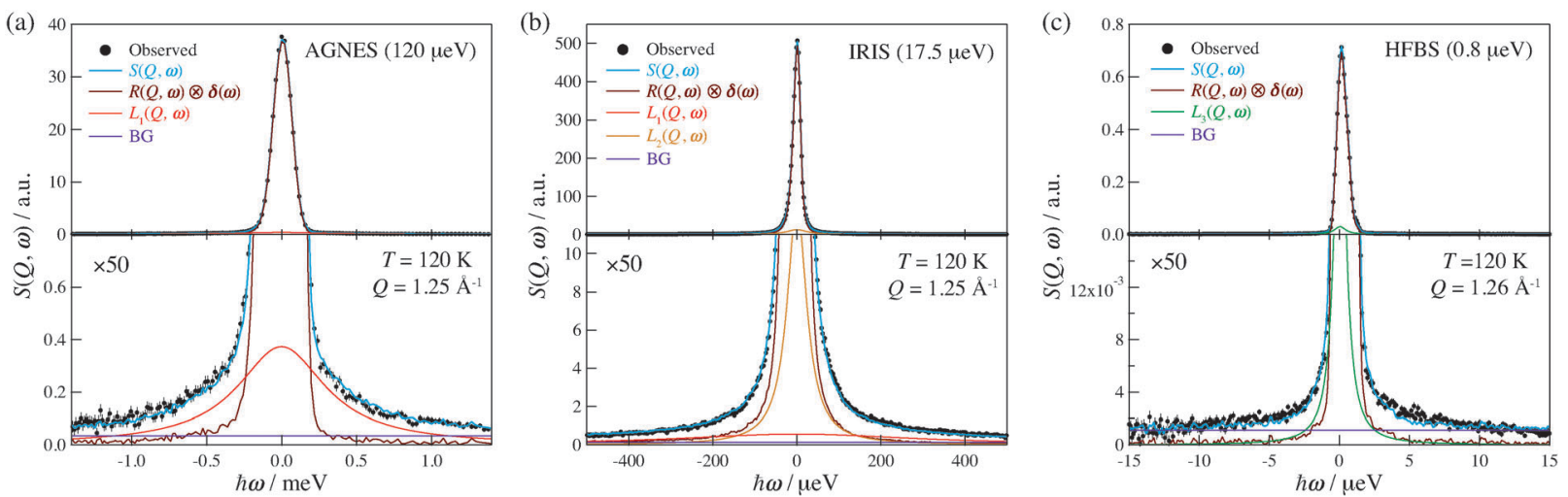

Fig. 7 QENS profiles of $\left(\mathrm{NH}_{4}\right)_{2}(\mathrm{adp})\left[\mathrm{Zn}_{2}(\mathrm{ox})_{3}\right] \cdot 3 \mathrm{H}_{2} \mathrm{O}$ obtained by (a) AGNES, (b) IRIS, and (c) HFBS spectrometers. All data are taken at $Q \simeq 1.25 \AA^{-1}$ and $T=120 \mathrm{~K}$. The lower panels display the enlarged plot in the vertical axis. Error bars throughout the text represent one standard deviation. Solid curves represent the results of the fitting analyses. See text for the details.
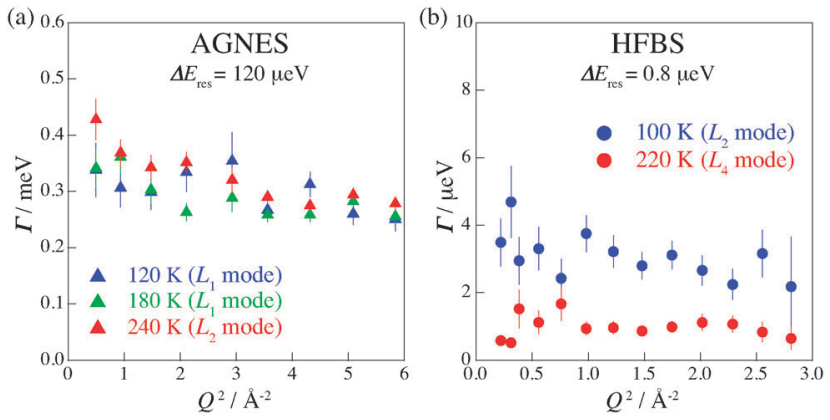

Fig. 8 Q-dependence of $\Gamma$ estimated from the fitting for the data taken on (a) AGNES and (b) HFBS spectrometers.

The mechanisms of the proton diffusion assisted by water molecules are roughly divided into two: i.e., one is the Vehicle mechanism in which a water molecule having a proton, that is a hydronium ion $\left(\mathrm{H}_{3} \mathrm{O}^{+}\right)$, carries a proton for a long distance ${ }^{34}$ and the other is the Grotthuss mechanism in which a hydronium ion reorients and passes a proton to a neighboring water molecules through a hydrogen bond. ${ }^{35,36}$ In $\left(\mathrm{NH}_{4}\right)_{2}(\operatorname{adp})\left[\mathrm{Zn}_{2}(\mathrm{ox})_{3}\right] \cdot 3 \mathrm{H}_{2} \mathrm{O}$, all of the motions related to hydrogen atoms are local relaxations as mentioned above. We thus conclude that the protons in $\left(\mathrm{NH}_{4}\right)_{2}(\operatorname{adp})\left[\mathrm{Zn}_{2}(\mathrm{Ox})_{3}\right] \cdot 3 \mathrm{H}_{2} \mathrm{O}$ are carried through the Grotthuss mechanism.

3.4.2 Arrhenius plot. Fig. 9 shows the Arrhenius plot of relaxation times for $\left(\mathrm{NH}_{4}\right)_{2}(\operatorname{adp})\left[\mathrm{Zn}_{2}(\mathrm{ox})_{3}\right] \cdot 3 \mathrm{H}_{2} \mathrm{O}$ and $\mathrm{K}_{2}(\operatorname{adp})-$ $\left[\mathrm{Zn}_{2}(\mathrm{ox})_{3}\right] \cdot 3 \mathrm{H}_{2} \mathrm{O}$. The relaxation times are evaluated from the relation, $\tau=1 / \Gamma$, for the Lorentz functions. Here, the $\Gamma$ data for all $Q$ values are summed up because no $Q$ dependence on $\Gamma$ was observed as described before. The average $Q$ value was $1.25 \AA^{-1}$.

There exist four relaxation modes $\left(L_{1}, L_{2}, L_{3}\right.$, and $\left.L_{4}\right)$ in $\left(\mathrm{NH}_{4}\right)_{2}(\operatorname{adp})\left[\mathrm{Zn}_{2}(\mathrm{ox})_{3}\right] \cdot 3 \mathrm{H}_{2} \mathrm{O}$. These relaxation modes were observed by two different instruments though their observation temperatures are sometimes different. This fact increases the reliability of the analysis and the related discussion. It is noteworthy that the data of each relaxation lie on each straight line, meaning that all relaxations follow the Arrhenius law in the whole temperature range. For each relaxation mode, the

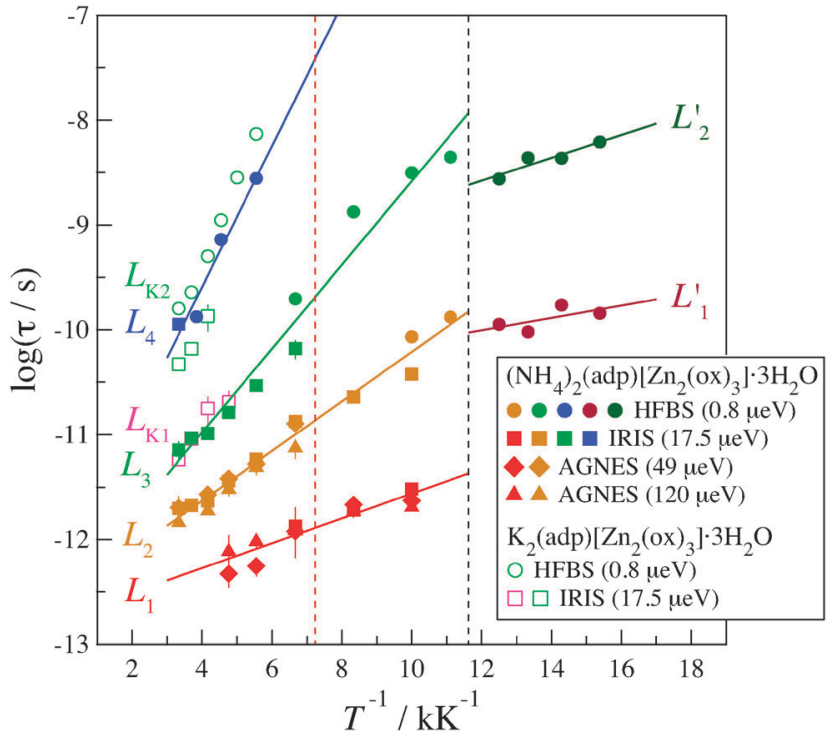

Fig. 9 Arrhenius plot for the relaxation times of $\left(\mathrm{NH}_{4}\right)_{2}(\operatorname{adp})\left[\mathrm{Zn}_{2}(\mathrm{ox})_{3}\right]$. $3 \mathrm{H}_{2} \mathrm{O}$ (filled symbols) and $\mathrm{K}_{2}(\mathrm{adp})\left[\mathrm{Zn}_{2}(\mathrm{ox})_{3}\right] \cdot 3 \mathrm{H}_{2} \mathrm{O}$ (open symbols) at $Q_{\mathrm{av}}=1.25 \AA^{-1}$. The circle, square, diamond, and triangle symbols represent the data measured on HFBS $(0.8 \mu \mathrm{eV})$, IRIS $(17.5 \mu \mathrm{eV})$, AGNES $(49 \mu \mathrm{eV})$, and AGNES $(120 \mu \mathrm{eV})$, respectively; the number in the parenthesis denotes the energy resolution of each instrument. Each relaxation is labeled as $L_{i}$ (for $\left(\mathrm{NH}_{4}\right)_{2}(\operatorname{adp})\left[\mathrm{Zn}_{2}(\mathrm{ox})_{3}\right] \cdot 3 \mathrm{H}_{2} \mathrm{O}$ ) and $L_{\mathrm{K} i}$ (for $\mathrm{K}_{2}(\operatorname{adp})\left[\mathrm{Zn}_{2}(\mathrm{ox})_{3}\right] \cdot 3 \mathrm{H}_{2} \mathrm{O}$ ). The dashed black and red lines are the transition temperatures of $\left(\mathrm{NH}_{4}\right)_{2}(\operatorname{adp})$ $\left[\mathrm{Zn}_{2}(\mathrm{Ox})_{3}\right] \cdot 3 \mathrm{H}_{2} \mathrm{O}$ and $\mathrm{K}_{2}(\mathrm{adp})\left[\mathrm{Zn}_{2}(\mathrm{ox})_{3}\right] \cdot 3 \mathrm{H}_{2} \mathrm{O}$, respectively.

activation energy, $\Delta E_{\mathrm{a}}$, of the relaxation is obtained from the slope of the plots assuming the Arrhenius equation

$$
\log \tau=\log \tau_{0}+\frac{\Delta E_{\mathrm{a}}}{R T}
$$

where $R\left(=8.314 \mathrm{~J} \mathrm{~K}^{-1} \mathrm{~mol}^{-1}\right)$ is the gas constant and $\tau_{0}$ is the relaxation time at infinite temperature. The activation energy for each relaxation is shown in Table 1 . It is remarkable that the activation energies of $L_{1}$ and $L_{2}$ are very small compared with the rotational activation energies of $\mathrm{H}_{2} \mathrm{O}$ and $\mathrm{NH}_{4}^{+}$in condensed phases, e.g., $17 \mathrm{~kJ} \mathrm{~mol}^{-1}$ in bulk water and $20 \mathrm{~kJ} \mathrm{~mol}^{-1}$ in solid $\mathrm{NH}_{4} \mathrm{Cl}$. 
Table 1 Activation energy $\left(\Delta E_{\mathrm{a}}\right)$ for each mode in $\left(\mathrm{NH}_{4}\right)_{2}(\mathrm{adp})\left[\mathrm{Zn}_{2}(\mathrm{Ox})_{3}\right] \cdot 3 \mathrm{H}_{2} \mathrm{O}$

\begin{tabular}{llll}
\hline Mode & $\Delta E_{\mathrm{a}}\left(T>T_{\text {trs }}\right)$ & Mode & $\Delta E_{\mathrm{a}}\left(T<T_{\mathrm{trs}}\right)$ \\
\hline$L_{1}$ & $2.3 \mathrm{~kJ} \mathrm{~mol}^{-1}$ & $L_{1}{ }^{\prime}$ & $1.1 \mathrm{~kJ} \mathrm{~mol}^{-1}$ \\
$L_{2}$ & $4.5 \mathrm{~kJ} \mathrm{~mol}^{-1}$ & $L_{2}{ }^{\prime}$ & $2.1 \mathrm{~kJ} \mathrm{~mol}^{-1}$ \\
$L_{3}$ & $7.7 \mathrm{~kJ} \mathrm{~mol}^{-1}$ & & \\
$L_{4}$ & $12.9 \mathrm{~kJ} \mathrm{~mol}^{-1}$ & &
\end{tabular}

On the other hand, in $\mathrm{K}_{2}(\operatorname{adp})\left[\mathrm{Zn}_{2}(\mathrm{ox})_{3}\right] \cdot 3 \mathrm{H}_{2} \mathrm{O}$, only two relaxations $L_{\mathrm{K} 1}$ and $L_{\mathrm{K} 2}$ were observed around the positions of $L_{3}$ and $L_{4}$ of $\left(\mathrm{NH}_{4}\right)_{2}(\mathrm{adp})\left[\mathrm{Zn}_{2}(\mathrm{ox})_{3}\right] \cdot 3 \mathrm{H}_{2} \mathrm{O}$, respectively. From the results mentioned above, it is reasonably concluded that $L_{1}$ and $L_{2}$ of $\left(\mathrm{NH}_{4}\right)_{2}(\operatorname{adp})\left[\mathrm{Zn}_{2}(\mathrm{ox})_{3}\right] \cdot 3 \mathrm{H}_{2} \mathrm{O}$ are associated with the motions of $\mathrm{NH}_{4}{ }^{+}$ions, while $L_{3}, L_{4}, L_{\mathrm{K} 1}$, and $L_{\mathrm{K} 2}$ are the motions of $\mathrm{H}_{2} \mathrm{O}$ molecules. The small activation energies of the $L_{1}$ and $L_{2}$ modes reflect the fact that the hydrogen bonds of ammonium ions are weaker than those of water molecules. We accept the possibility that the slowest mode $\left(L_{4}\right)$ is assigned to the relaxation of $\mathrm{COOH}$ groups of adipic acid.

Why do two different types of motions related to ammonium ions exist? From the structural data obtained by the single crystal X-ray diffraction, ${ }^{22}$ the two $\mathrm{NH}_{4}{ }^{+}$ions are located at the crystallographically equivalent sites. On the other hand, there are two crystallographically distinct sites for the three $\mathrm{H}_{2} \mathrm{O}$ molecules; two $\mathrm{H}_{2} \mathrm{O}$ molecules are located in the two crystallographically equivalent sites, whereas the $3 \mathrm{rd} \mathrm{H}_{2} \mathrm{O}$ molecule is positionally disordered between another two equivalent sites with an occupancy of $50 \%$. The $\mathrm{NH}_{4}{ }^{+}$ions may be affected by the presence or absence of adjacent water molecules, and may have different activation energies.

Next, we discuss the relation between the phase transitions and the relaxation motions. In $\left(\mathrm{NH}_{4}\right)_{2}(\operatorname{adp})\left[\mathrm{Zn}_{2}(\mathrm{ox})_{3}\right] \cdot 3 \mathrm{H}_{2} \mathrm{O}$, the relaxations obviously changed at the transition temperature as shown in Fig. 9. It was confirmed that there is no relaxation below the transition temperature in a shorter time region of $L_{1}{ }^{\prime}$. This measurement was performed by DCS (NCNR, NIST, USA), ${ }^{37}$ a chopper spectrometer suitable for a time region between $10^{-10} \mathrm{~S}$ and $10^{-12} \mathrm{~s}$. In general, molecular/ionic motions do not become faster below the transition temperature; therefore, it is speculated that the two relaxations observed below the transition temperature are the motions of ammonium ions. It is interesting to note that the activation energy below the transition temperature is lower than that above the temperature. It may suggest that the quantum tunneling plays a role in the relaxational process. Further studies are required to address this issue.

In $\mathrm{K}_{2}(\operatorname{adp})\left[\mathrm{Zn}_{2}(\mathrm{ox})_{3}\right] \cdot 3 \mathrm{H}_{2} \mathrm{O}$, no relaxation was observed below the transition temperature. This suggests that the carboxyl groups and water molecules become frozen at the transition temperature, $138 \mathrm{~K}$. Thus, the phase transition of $\left(\mathrm{NH}_{4}\right)_{2}(\operatorname{adp})\left[\mathrm{Zn}_{2}(\mathrm{ox})_{3}\right] \cdot 3 \mathrm{H}_{2} \mathrm{O}$ at $86 \mathrm{~K}$ is entirely different from that of $\mathrm{K}_{2}(\operatorname{adp})\left[\mathrm{Zn}_{2}(\mathrm{ox})_{3}\right] \cdot 3 \mathrm{H}_{2} \mathrm{O}$ at $138 \mathrm{~K}$

3.4.3 Elastic incoherent structure factor. We have made further analysis on the two local relaxations of ammonium ions $\left(L_{1}\right.$ and $L_{2}$ ). For the local motion, $\Gamma(Q)$ does not give us any geometrical information, but the relative integrated intensities do via the elastic incoherent structure factor (EISF), $A_{0}(Q)$. This is defined as

$$
A_{0}(Q)=\frac{I_{\text {elastic }}(Q)}{I_{\text {elastic }}(Q)+I_{\mathrm{QENS}}(Q)}
$$

where $I_{\text {elastic }}$ and $I_{\mathrm{QENS}}$ are the peak intensities of elastic and quasi-elastic scatterings, respectively. Fig. 10 shows the EISFs of the $L_{1}$ and $L_{2}$ relaxations measured at $120 \mathrm{~K}$ as a function of momentum transfer $Q$. For other relaxations, which were measured on HFBS, it was difficult to obtain analyzable $A_{0}(Q)$ probably because the detector efficiencies of HFBS were not corrected appropriately against $Q$ in our experiment. It was also difficult to analyze the data at higher temperatures since two relaxations, e.g., $L_{1}$ and $L_{2}$, approach each other as shown in Fig. 9.

The EISF varies as a function of $Q$, depending on the dynamical model. ${ }^{38,39}$ In an ammonium ion, four hydrogen atoms surround a central nitrogen atom with tetrahedral symmetry. The contribution from the incoherent scattering of nitrogen atoms
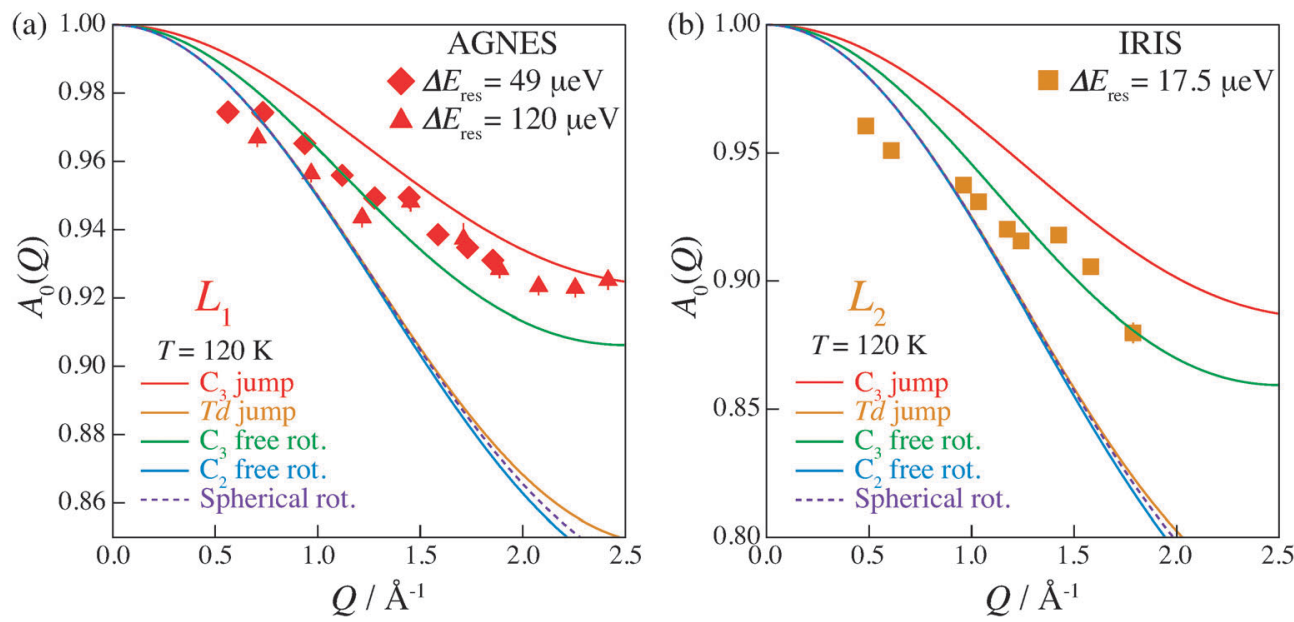

(c)

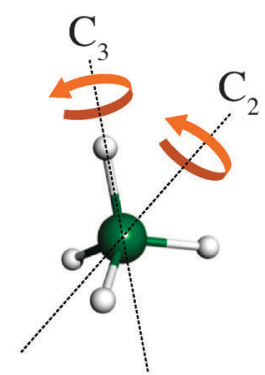

Fig. 10 Elastic incoherent structure factor (EISF) of $\left(\mathrm{NH}_{4}\right)_{2}(\mathrm{adp})\left[\mathrm{Zn}_{2}(\mathrm{Ox})_{3}\right] \cdot 3 \mathrm{H}_{2} \mathrm{O}$ for (a) the $L_{1}$ mode measured by AGNES and (b) the $L_{2}$ mode measured by IRIS. Solid curves represent the calculated EISF based on several model functions. See text for the details. (c) Structure of ammonium ions composed of four hydrogen atoms (white) and a nitrogen atom (green). The twofold $\left(C_{2}\right)$ and threefold $\left(C_{3}\right)$ axes are exhibited. 
can be neglected, so that the incoherent scattering reflects only the motion of the hydrogen atoms. We considered several dynamic models; a jump about a threefold axis ( $C_{3}$ jump), a jump among the apices of a tetrahedron ( $T_{\mathrm{d}}$ jump), a continuous rotation about a threefold axis $\left(C_{3}\right.$ free rot.), a continuous rotation about a twofold axis ( $C_{2}$ free rot.), and an isotropic rotation on the circumscribed sphere of the tetrahedron (Spherical rot.). Note that a jump about the $C_{2}$ axis is indistinguishable from that about the $C_{3}$ axis. The $A_{0}$ s for the reorientation of the ammonium ion are given by

$$
\begin{gathered}
A_{0}\left(C_{3} \text { jump }\right)=\frac{1}{2}\left\{1+j_{0}\left(\sqrt{\frac{8}{3}} Q r\right)\right\} \\
A_{0}\left(T_{\text {d jump })}=\frac{1}{4}\left\{1+3 j_{0}\left(\sqrt{\frac{8}{3}} Q r\right)\right\}\right. \\
A_{0}\left(C_{3} \text { free rot. }\right)=\frac{1}{4}\left\{1+3 J_{0}^{2}\left(\frac{\sqrt{8}}{3} Q r\right)\right\} \\
\left.A_{0}\left(C_{2} \text { free rot. }\right)=J_{0}^{2}\left(\sqrt{\frac{2}{3}} Q r\right)^{2}\right) \\
A_{0} \text { (Spherical rot.) }=j_{0}^{2}(Q r),
\end{gathered}
$$

where $r$ is the distance between the hydrogen and nitrogen atoms, and $J_{0}$ and $j_{0}$ are 0 th order of the Bessel and spherical Bessel functions, respectively. In this calculation, $r$ was fixed to be a literature value $(1.0 \AA)$. The calculated $A_{0}(Q)$ s are also plotted in Fig. 10. It can be concluded that the ammonium ions likely perform a continuous rotation around the $C_{3}$ axis while jumping between two preferred orientations.

\subsection{Proton conducting path}

Finally, we discuss proton conducting pathways in $\left(\mathrm{NH}_{4}\right)_{2}(\mathrm{adp})-$ $\left[\mathrm{Zn}_{2}(\mathrm{Ox})_{3}\right] \cdot 3 \mathrm{H}_{2} \mathrm{O}$ and $\mathrm{K}_{2}(\mathrm{adp})\left[\mathrm{Zn}_{2}(\mathrm{ox})_{3}\right] \cdot 3 \mathrm{H}_{2} \mathrm{O}$. As mentioned before, the protons are carried through the Grotthuss mechanism with $\mathrm{H}_{2} \mathrm{O}$ molecules, $\mathrm{NH}_{4}{ }^{+}$ions (for $\left(\mathrm{NH}_{4}\right)_{2}(\operatorname{adp})\left[\mathrm{Zn}_{2}(\mathrm{ox})_{3}\right]$. $3 \mathrm{H}_{2} \mathrm{O}$ ), and $-\mathrm{COOH}$ groups of adipic acid located in the proton conducting layers. Since the positions of hydrogen atoms were not determined by the X-ray diffraction, ${ }^{22}$ we consider the oxygen and nitrogen atoms which can be associated with the hydrogen bonds. Table 2 lists the possible hydrogen bonds with bond lengths shorter than $3.1 \AA$ A that can be considered to be the largest limit for the hydrogen-bond formation. The number of hydrogen bonds in $\left(\mathrm{NH}_{4}\right)_{2}(\operatorname{adp})\left[\mathrm{Zn}_{2}(\mathrm{ox})_{3}\right] \cdot 3 \mathrm{H}_{2} \mathrm{O}$ is three times larger than that in $\mathrm{K}_{2}(\mathrm{adp})\left[\mathrm{Zn}_{2}(\mathrm{ox})_{3}\right] \cdot 3 \mathrm{H}_{2} \mathrm{O}$. These bonds are schematically shown in Fig. 11 and 12 for $\left(\mathrm{NH}_{4}\right)_{2}(\operatorname{adp})\left[\mathrm{Zn}_{2}(\mathrm{ox})_{3}\right]$. $3 \mathrm{H}_{2} \mathrm{O}$ and $\mathrm{K}_{2}(\operatorname{adp})\left[\mathrm{Zn}_{2}(\mathrm{ox})_{3}\right] \cdot 3 \mathrm{H}_{2} \mathrm{O}$, respectively. There exists an obvious hydrogen-bond network in the proton conducting layers of $\left(\mathrm{NH}_{4}\right)_{2}(\mathrm{adp})\left[\mathrm{Zn}_{2}(\mathrm{ox})_{3}\right] \cdot 3 \mathrm{H}_{2} \mathrm{O}$. On the other hand, hydrogen bonds neither form a network nor percolate over the proton conducting layer in $\mathrm{K}_{2}(\mathrm{adp})\left[\mathrm{Zn}_{2}(\mathrm{Ox})_{3}\right] \cdot 3 \mathrm{H}_{2} \mathrm{O}$. Evidently, the ammonium ions have a key role in forming the

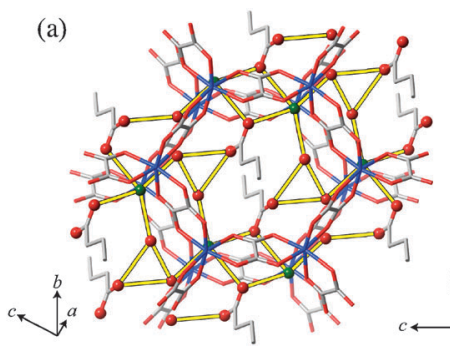

(b)

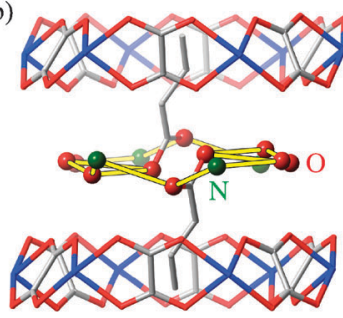

Fig. 11 Possible hydrogen-bond arrangements in $\left(\mathrm{NH}_{4}\right)_{2}(\operatorname{adp})\left[\mathrm{Zn}_{2}(\mathrm{ox})_{3}\right]$. $3 \mathrm{H}_{2} \mathrm{O}$. Yellow thick lines represent hydrogen bonds whose length is shorter than $3.1 \AA$. (a) Perspective view along the a-axis. (b) Perspective view along the $b$-axis.
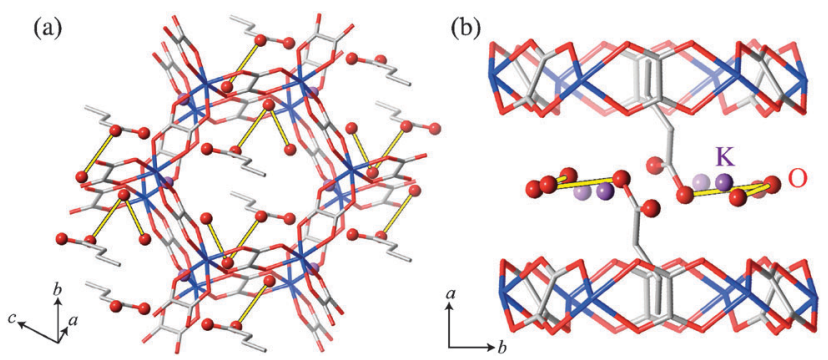

Fig. 12 Possible hydrogen-bond arrangements in $\mathrm{K}_{2}(\operatorname{adp})\left[\mathrm{Zn}_{2}(\mathrm{ox})_{3}\right] \cdot 3 \mathrm{H}_{2} \mathrm{O}$. Yellow thick lines represent hydrogen bonds whose length is shorter than $3.1 \AA$. (a) Perspective view along the a-axis. (b) Perspective view along the $b$-axis.

Table 2 Possible hydrogen bonds in $\left(\mathrm{NH}_{4}\right)_{2}(\operatorname{adp})\left[\mathrm{Zn}_{2}(\mathrm{ox})_{3}\right] \cdot 3 \mathrm{H}_{2} \mathrm{O}$ and $\mathrm{K}_{2}(\operatorname{adp})\left[\mathrm{Zn}_{2}(\mathrm{ox})_{3}\right] \cdot 3 \mathrm{H}_{2} \mathrm{O}$. Only atoms associated with hydrogen bonds are considered; oxygen atoms of the carboxyl groups in adipic acids $(O(7)$ and $O(8)$ ), oxygen atoms of water molecules $(O(9)$ and $O(10))$, and nitrogen atoms of ammonium ions (N(1)). The sets with the bond length shorter than $3.1 \AA$ are shown here

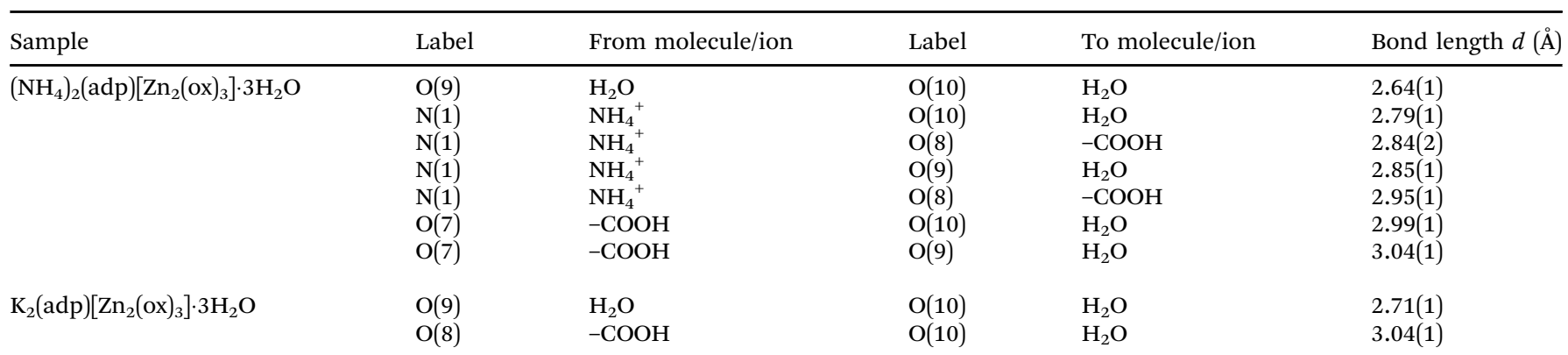


hydrogen-bond network; there are 3-4 hydrogen bonds between $\mathrm{N}(1)$ and $\mathrm{O}(n)(n=8,9,10)$. We speculate that the high proton conductivity in $\left(\mathrm{NH}_{4}\right)_{2}(\mathrm{adp})\left[\mathrm{Zn}_{2}(\mathrm{ox})_{3}\right] \cdot 3 \mathrm{H}_{2} \mathrm{O}$ is realized not only by many proton conducting paths but also by the high mobility of ammonium ions (rotation around the $C_{3}$ axis with small activation energy). This would have to be confirmed through the determination of the exact positions of hydrogen atoms forming the hydrogen bonds.

\section{Conclusion}

In this paper, in order to elucidate the relation between the proton conductivity and phase transitions, we have performed adiabatic calorimetry and neutron powder diffraction experiments for $\left(\mathrm{NH}_{4}\right)_{2}(\mathrm{adp})\left[\mathrm{Zn}_{2}(\mathrm{ox})_{3}\right] \cdot 3 \mathrm{H}_{2} \mathrm{O}$ and $\mathrm{K}_{2}(\mathrm{adp})\left[\mathrm{Zn}_{2}(\mathrm{ox})_{3}\right]$. $3 \mathrm{H}_{2} \mathrm{O}$, as well as QENS measurements to get insights into the mechanism for proton conduction. The adiabatic calorimetry revealed that $\left(\mathrm{NH}_{4}\right)_{2}(\mathrm{adp})\left[\mathrm{Zn}_{2}(\mathrm{ox})_{3}\right] \cdot 3 \mathrm{H}_{2} \mathrm{O}$ and $\mathrm{K}_{2}(\operatorname{adp})\left[\mathrm{Zn}_{2}(\mathrm{ox})_{3}\right]$. $3 \mathrm{H}_{2} \mathrm{O}$ exhibit higher-order phase transitions at $86 \mathrm{~K}$ and $138 \mathrm{~K}$, respectively. These transitions were also observed by the neutron powder diffraction measurement and the fixed window scan. In the QENS measurements, since $\Gamma$ (HWHM of Lorentz function) is independent of $Q$, it is evident that the protons in $\left(\mathrm{NH}_{4}\right)_{2}(\operatorname{adp})\left[\mathrm{Zn}_{2}(\mathrm{Ox})_{3}\right] \cdot 3 \mathrm{H}_{2} \mathrm{O}$ are carried through the Grotthuss mechanism. By using the three spectrometers with different energy resolutions, we have succeeded to observe the overall feature of dynamics: there exist four and two relaxation motions in $\left(\mathrm{NH}_{4}\right)_{2}(\operatorname{adp})\left[\mathrm{Zn}_{2}(\mathrm{ox})_{3}\right] \cdot 3 \mathrm{H}_{2} \mathrm{O}$ and $\mathrm{K}_{2}(\operatorname{adp})\left[\mathrm{Zn}_{2}(\mathrm{ox})_{3}\right] \cdot 3 \mathrm{H}_{2} \mathrm{O}$, respectively. It is speculated that two fast rotational motions of ammonium ions having very small activation energy play a key role in the high proton conductivity in $\left(\mathrm{NH}_{4}\right)_{2}(\mathrm{adp})\left[\mathrm{Zn}_{2}(\mathrm{ox})_{3}\right]$. $3 \mathrm{H}_{2} \mathrm{O}$. We discuss the hydrogen-bond pathways in proton conducting layers using the previous structural data. We found that hydrogen-bond networks are well constructed by $\mathrm{H}_{2} \mathrm{O}$ and $\mathrm{NH}_{4}{ }^{+}$ in $\left(\mathrm{NH}_{4}\right)_{2}(\operatorname{adp})\left[\mathrm{Zn}_{2}(\mathrm{ox})_{3}\right] \cdot 3 \mathrm{H}_{2} \mathrm{O}$. This network can contribute to the Grotthuss mechanism of proton conduction. In order to further investigate the proton conducting mechanism, it is essential to determine the crystal structure and specifically the positions of the $\mathrm{H}$ atoms by means of a high resolution neutron diffractometer.

\section{Disclaimer}

The identification of commercial products does not imply endorsement by the National Institute of Standards and Technology nor does it imply that these are the best for the purpose.

\section{Acknowledgements}

The authors thank Dr John R. D. Copley (NCNR, NIST) for the DCS measurement, and Dr Kunihisa Sugimoto (SPring-8) and Dr Akihito Fujiwara (SPring-8) for the single-crystal X-ray diffraction measurement at low temperature. The HFBS experiment at NCNR was financially supported by Institute for Solid State Physics, the University of Tokyo, through the Travel
Expense Support for the Overseas program. This work utilized facilities supported in part by the National Science Foundation under Agreement No. DMR-0944772.

\section{References}

1 H. K. Chae, D. Y. Siberio-Perez, J. Kim, Y. Go, M. Eddaoudi, A. J. Matzger, M. O'Keeffe and O. M. Yaghi, Nature, 2004, 427, 523.

2 X. Zhao, B. Xiao, J. A. Fletcher, K. M. Thomas, D. Bradshaw and M. J. Rosseinsky, Science, 2004, 306, 1012.

3 R. Matsuda, R. Kitaura, S. Kitagawa, Y. Kubota, R. V. Beloslusov, T. C. Kobayashi, H. Sakamoto, T. Chiba, M. Tanaka, Y. Kawazoe and Y. Mita, Nature, 2005, 436, 238.

4 J. S. Seo, D. Whang, H. Lee, S. I. Jun, J. Oh, Y. J. Jeon and K. Kim, Nature, 2000, 404, 982.

5 C.-D. Wu, A. Hu, L. Zhang and W. Lin, J. Am. Chem. Soc., 2005, 127, 8940.

6 H. Kitagawa, Y. Nagao, M. Fujishima, R. Ikeda and S. Kanda, Inorg. Chem. Commun., 2003, 6, 346.

7 H. Ōkawa, M. Sadakiyo, T. Yamada, M. Maesato, M. Ohba and H. Kitagawa, J. Am. Chem. Soc., 2013, 135, 2256.

8 M. Sadakiyo, H. Ōkawa, A. Shigematsu, M. Ohba, T. Yamada and H. Kitagawa, J. Am. Chem. Soc., 2012, 134, 5472.

9 G. Xu, K. Otsubo, T. Yamada, S. Sakaida and H. Kitagawa, J. Am. Chem. Soc., 2013, 135, 7438.

10 J. M. Taylor, R. K. Mah, I. L. Moudrakovski, C. I. Ratcliffe, R. Vaidhyanathan and G. K. H. Shimizu, J. Am. Chem. Soc., 2010, 132, 14055.

11 N. C. Jeong, B. Samanta, C. Y. Lee, O. K. Farha and J. T. Hupp, J. Am. Chem. Soc., 2012, 134, 51.

12 D. Umeyama, S. Horike, M. Inukai, Y. Hijikata and S. Kitagawa, Angew. Chem., Int. Ed., 2011, 50, 1.

13 G. Ferey, C. Mellot-Draznieks, C. Serre and F. Millange, Acc. Chem. Res., 2005, 38, 217.

14 S. Kitagawa, R. Kitaura and S. Noro, Angew. Chem., Int. Ed., 2004, 43, 2334.

15 O. M. Yaghi, M. O’Keeffe, N. W. Ockwig, H. K. Chae, M. Eddaoudi and J. Kim, Nature, 2003, 423, 705.

16 K. D. Kreuer, S. J. Paddison, E. Spohr and M. Schuster, Chem. Rev., 2004, 104, 4637.

17 K. D. Kreuer, Chem. Mater., 1996, 8, 610.

18 B. C. Steele and A. Heinzel, Nature, 2001, 414, 345.

19 Y. Nagao, R. Ikeda, S. Kanda, Y. Kubozono and H. Kitagawa, Mol. Cryst. Liq. Cryst., 2002, 379, 89.

20 Y. Nagao, M. Fujishima, S. Kanda, R. Ikeda and H. Kitagawa, Synth. Met., 2003, 133-134, 431.

21 T. Yamada, M. Sadakiyo and H. Kitagawa, J. Am. Chem. Soc., 2009, 131, 3144.

22 M. Sadakiyo, T. Yamada and H. Kitagawa, J. Am. Chem. Soc., 2009, 131, 9906.

23 S. Bureekaew, S. Horike, M. Higuchi, M. Mizuno, T. Kawamura, D. Tanaka, N. Yanai and S. Kitagawa, Nat. Mater., 2009, 8, 831.

24 A. Shigematsu, T. Yamada and H. Kitagawa, J. Am. Chem. Soc., 2011, 133, 2034. 
25 T. Yamada, R. Yonamine, T. Yamada, H. Kitagawa and O. Yamamuro, J. Phys. Chem. B, 2010, 114, 8405.

26 T. Yamada, R. Yonamine, T. Yamada, H. Kitagawa, M. Tyagi, M. Nagao and O. Yamamuro, J. Phys. Chem. B, 2011, 115, 13563.

27 M. Sadakiyo, T. Yamada and H. Kitagawa, submitted.

28 O. Yamamuro, M. Oguni, T. Matsuo and H. Suga, Bull. Chem. Soc. Jpn., 1987, 60, 1269.

29 T. Kajitani, K. Shibata, S. Ikeda, M. Kohgi, H. Yoshizawa, K. Nemoto and K. Suzuki, Physica B, 1995, 213-214, 872.

30 O. Yamamuro, Y. Inamura, Y. Kawamura, S. Watanabe, T. Asami, H. Yoshizawa, Annual Report of Neutron Science Laboratory, Institute for Solid state Physics, University of Tokyo, 2005, 12, 12.

31 C. J. Carlile and M. A. Adams, Physica B, 1992, 182, 431.
32 A. Meyer, R. M. Dimeo, P. M. Gehring and D. A. Neumann, Rev. Sci. Instrum., 2003, 74, 2759.

33 R. T. Azuah, L. R. Kneller, Y. Qiu, P. L. W. Tregenna-Piggott, C. M. Brown, J. R. D. Copley and R. M. Dimeo, J. Res. Natl. Inst. Stand. Technol., 2009, 114, 341.

34 K. D. Kreuer, A. Rabenau and W. Weppner, Angew. Chem., Int. Ed. Engl., 1982, 21, 208.

35 N. Agmon, Chem. Phys. Lett., 1995, 244, 456.

36 X. Ke and I. Tanaka, Solid State Ionics, 2004, 172, 145.

37 J. R. D. Copley and J. C. Cook, Chem. Phys., 2003, 292, 477. 38 M. Bée, Physica B, 1992, 182, 323.

39 T. Yildirim, P. M. Gehring, D. A. Neumann, P. E. Eaton and T. Emrick, Phys. Rev. B: Condens. Matter Mater. Phys., 1999, 60, 314. 